\title{
AN INSPIRE-KONFORM 3D BUILDING MODEL OF BAVARIA USING CADASTRE INFORMATION, LIDAR AND IMAGE MATCHING
}

\author{
R. Roschlaub, J. Batscheider* \\ Bavarian Agency for Digitisation, High-Speed Internet and Surveying, Germany - \\ (robert.roschlaub, joachim.batscheider)@ldbv.bayern.de
}

Commission VI, WG VI/4

KEY WORDS: Cadastre, INSPIRE, CityGML, LoD2, LiDAR, Image Matching, Big Data

\begin{abstract}
:
The federal governments of Germany endeavour to create a harmonized 3D building data set based on a common application schema (the AdV-CityGML-Profile). The Bavarian Agency for Digitisation, High-Speed Internet and Surveying has launched a statewide 3D Building Model with standardized roof shapes for all 8.1 million buildings in Bavaria. For the acquisition of the 3D Building Model LiDAR-data or data from Image Matching are used as basis in addition with the building ground plans of the official cadastral map. The data management of the 3D Building Model is carried out by a central database with the usage of a nationwide standardized CityGML-Profile of the AdV. The update of the 3D Building Model for new buildings is done by terrestrial building measurements within the maintenance process of the cadaster and from image matching. In a joint research project, the Bavarian State Agency for Surveying and Geoinformation and the TUM, Chair of Geoinformatics, transformed an AdV-CityGML-Profilebased test data set of Bavarian LoD2 building models into an INSPIRE-compliant schema. For the purpose of a transformation of such kind, the AdV provides a data specification, a test plan for 3D Building Models and a mapping table. The research project examined whether the transformation rules defined in the mapping table, were unambiguous and sufficient for implementing a transformation of LoD2 data based on the AdV-CityGML-Profile into the INSPIRE schema. The proof of concept was carried out by transforming production data of the Bavarian 3D Building Model in LoD2 into the INSPIRE BU schema. In order to assure the quality of the data to be transformed, the test specifications according to the test plan for 3D Building Models of the AdV were carried out. The AdV mapping table was checked for completeness and correctness and amendments were made accordingly.
\end{abstract}

\section{INTRODUCTION}

In Germany surveying and mapping is assigned to the states. Therefore, nationwide projects need close cooperation and commitment by the states. "The Cadastral and Surveying Authorities of the states, which are responsible for the real estate cadastre and state survey (Official German Surveying and Mapping), cooperate within the Working Committee of the Surveying Authorities of the States of the Federal Republic of Germany (AdV, URL: http://www.adv-online.de) to discuss technical issues of fundamental and nationwide importance targeting standardized regulations." This includes the determination of common standards for the acquisition of $3 \mathrm{D}$ Building Models across Germany.

The surveying authorities of the states intend to build up a nationwide dataset of 3D Building Models based on a specialized schema (Gruber et al., 2014). In 2010, the AdV intended to offer a nationwide and uniform so called first detailed level (Level of Detail 1 - LoD1) dataset of BuildingModels from 2013 on. In the LoD1 data model, buildings are uniformly represented as blocks with a flat roof. The so called Level of Detail 2 (LoD2) is showing the buildings with standardized prototype roofs. The LoD2 dataset should have been built up during a mid-term timeframe.

In 2012, AdV decided a product standard for 3D Building Models. According to that, the building ground plans are derived from the official digital cadastral map and the buildings are uniformly represented as blocks with a flat roof in LoD1. Since mid-2013, a German-wide dataset of LoD1 objects is built up and offered to clients at the "Zentrale Stelle Hauskoordinaten und Hausumringe" (ZSHH), which is a central cross-national distribution agency. This central distribution agency is located at the government of the district Köln of North Rhine-Westphalia (NRW) (LA Geobasis, 2011). Meanwhile, all federal states of Germany finished the production of 3D-Building-Models in LoD1. Currently, almost all of the states are building up the dataset of 3D-BuildingModels in LoD2.

The data exchange between the states and the central service center uses a nationwide uniform profile of the AdV based on the City Geography Markup Language (CityGML) encoding standards from OpenGIS ${ }^{\circledR}$ and the Open Geospatial Consortium (OGC) Specification CityGML 1.0.0. (AdV, 2015a).

This AdV-CityGML-profile is also designed for the delivery of building data with standardized roof shapes in LoD2 with optional photo-realistic textures.

The degree of automatic recognition of roof shapes and the elevation accuracy of the automatic roof reconstruction are depending on the one hand on the degree of generalization of the roofs to the standard roof forms and on the other hand on the collection of data . If LiDAR-data (Light Detection And Ranging) from airborne laser scanning are used for the acquisition, then the density of the point cloud is significant. When oriented aerial photographs are used, the accuracy of the orientation elements and the point allocation determines the quality of positional and elevation accuracy. The use of building outlines simplifies the building reconstruction from LiDAR-

\footnotetext{
* Corresponding author.
} 
data and aerial images (Vosselman, 2002, Rottensteiner and Briese, 2003). The ISPRS benchmark on 3D Building reconstruction (Rottensteiner et al., 2012) contains three out of seven different methods, which use building outlines or building maps.

Independently from the data collection method and the underlying dataset an update after the first acquisition of a 3DBuilding Model has to be ensured. This requires a comprehensive concept containing the first acquisition, the data management and the update process combined in one workflow.

With the directive 2007/2/EC of the European Parliament and of the Council establishing an Infrastructure for Spatial Information in the European Community (INSPIRE) coming to effect in the year 2007 and its nationwide implementation in the federal states, there are to provide digital geospatial data in an interoperable way (Janowsky et al., 2010). The dataset of 3DBuilding Models created in the federal states is assigned to annex III of the INSPIRE Directive for the data specification of buildings (INSPIRE-BU).

In addition to the own target of the states to create a uniform dataset of 3D-Building Models in two levels of detail, based on nationwide standards of the $\mathrm{AdV}$, it is obvious to check the possibility to convert the data to an INSPIRE conform schema early.

For the conversion of the3D-Building Models in level of detail 2 to INSPIRE, the project Group "3D-Geobasisdaten" of the AdV created a first mapping table on the basis of AdVCityGML-profile and GeoInfoDok 7.0 beta. In extension of this work a joint research project of the Bavarian State Agency for Surveying and Geoinformation and the Technische Universität München (TUM), Chair of Geoinformatics, provided proof of convertibility of 3D-BuildingModels on AdV-standards to INSPIRE by a sample (Aringer et al. 2015). The test plan and test specifications committed by the project Group "3DGebasisdaten" of the AdV together with the ZSHH was to be examined and applied as well.

The task is to map the 3D-Building Models, based on AdVCityGML-profile considering GeoInfoDok 7.0 to an INSPIRE compliant schema. The review of GeoInfoDok 7.0 beta was finished in April 2014. Nevertheless it will be necessary to continue analyzing these documents to discover bugs or ambiguities in the INSPIRE specifications, the AdV-CityGML profile or the GeoInfoDok in terms of the coming transformation of the schemata in order to initiate an update of such a document if necessary. The production of 3D-Building Models in the second level of detail has already started in most of the federal states in Germany. If an inconsistency would have been found it would have been useful to cause an update of the software in use without changing documents to reduce faulty 3D Building Models. In the joint research project the special mapping table of the AdV was examined and a concept for the transformation was developed and implemented as a prototype. First, the extraction of the data and the concept of updating and data management will be described. Later on the elements of the semantic transformation to INSIRE will be explained.

\section{THE FIRST CALCULATION AND UPDATE CONCEPT}

Since 2012 LiDAR-data with a point density between 1 and 4 points per square meter are available in Bavaria. This data are suitable for calculating a precise digital elevation model (DEM) as well as a surface model. Currently the DEM is available in a minimum grid spacing of $1 \mathrm{~m}$ for Bavaria.
Together with the building ground plans from the cadastre, LiDAR-data are suited for the first acquisition of a 3D-Building Model (Schilcher et al., 1998, 1999, Aringer and Roschlaub, 2014). The intersection of the building ground plans with the DEM provides the building root points. The DSM is used as data basis for the roof recognition. In the following, the task of recognizing roofs automatically from LiDAR-data is described. Subsequently the Bavarian method for the initial acquisition of a nationwide 3D Building Model is described.

\subsection{Semiautomatic realization of the first acquisition}

Since LiDAR-data is available Bavarian-wide the 3D Building Models can be calculated from an existing laser point cloud. The technical realization of the previous described problem of automated roof recognition has been solved differently by existing software packages of the shelf for the derivation of 3DBuilding Models.

The approach of the software "Building-Reconstruction" of Virtual City SYSTEMS (VCS) first runs a planimetric fragmentation and then approximates the complete standard roof shape. The roof shape that fits best is applied. Afterwards the roof surfaces of this roof shape are fitted systematically as good as possible. In contrast to many other solutions, VCS meets Bavaria's required planimetric constancy for buildings of the cadastre. With this it is ensured that no additional data set besides the cadastre is established. In fact, the compliance of the planimetric constancy offers the possibility to fully convert the cadastre to $3 \mathrm{D}$ in a more simple form later on (figure 1).

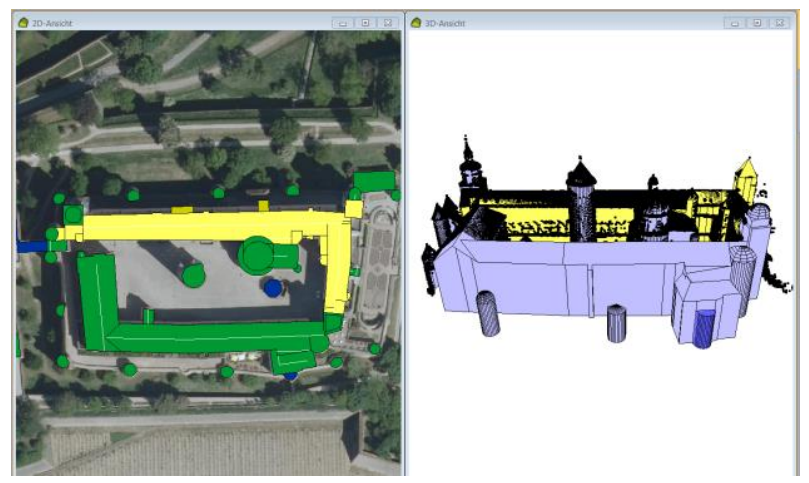

Figure 1. DOP with building ground plans (left) and corresponding laser point cloud of a building in yellow which needs to be edited (right)

The degree of automatic roof recognition can be expressed by the post-editing rate. It is basically dependent on the density and type of the buildings. In modern cities for example the postediting rate is only $15 \%$. The higher the percentage of historical buildings, the lesser the automatic recognition rate of the roofs. The post-editing rate can be between $20 \%$ and $40 \%$.

The point density of the laser data influences the post-editing rate too. In an area with new buildings with typical German row houses and a laser point density of approximately 0.7 points per square meter the post-editing rate varies from about $25 \%$ up to $30 \%$, whereas with a point density of approximately 4.8 points per square meter the rate drops to $16 \%$.

\subsection{Update within the scope of the continuation of the land registry}

Currently the cadastre in Germany is two dimensional. If needed, additional information for the third dimension can be kept as an attribute. With this method the points forming the building as "special building points" with height details and 
information about the specific roof shape of a certain building can be saved in the cadastre. If the roof of a building consists of multiple roof shapes, these can be divided using construction element creation (Aringer and Hümmer, 2011).

The cadastre in Bavaria currently does not contain such 3Dinformation. After derivation of the standardized roofs of the 3D-Building Model with the semi-automated first data acquisition, these data can also improve the two dimensional cadastre. So, a significant added value arises for the cadastre.

If this information is to be used for updating, the challenge is that the data need to be inversely convertible from the second dimension unambiguously to the third dimension. If multiple roof shapes exist per building ground plan, the principle of the subdivision of buildings in components is used.
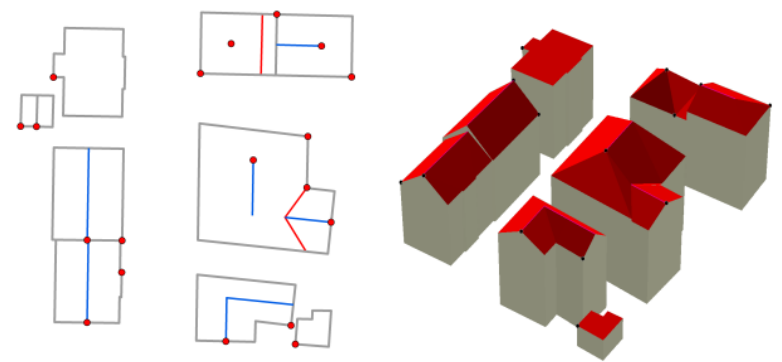

Figure 2. From the building ground plan (left) to the 3D Model (right)

Figure 2 shows buildings with roof shapes which are divided into components by the red lines. Blue lines however represent the ridge lines of the roofs. The red points represent ridge and eave points which are attributed as „special” building points with a relative height specification in the cadastre. Together with the ridges and the lines that separate the components a unique reconstruction of the roof geometry from the cadastral two dimensional data is possible. This still needs to be implemented programmatically in Bavaria.

After completion of the first data acquisition and the space closure, the 3D Building Model is continually updated by the regular maintenance of the cadastre in Bavaria (figure 3). Then neither LiDAR-data nor a DSM from image matching are required, since the cadastral measured building roof shapes are used. If multiple roof shapes for a building exist, these are divided into components. Additionally the ridge lines of a roof shape and the height of selected "special" building points (ridge and eave points) are calculated. With this information the third dimension can be reconstructed and thereby the 3D Building Model can be updated.
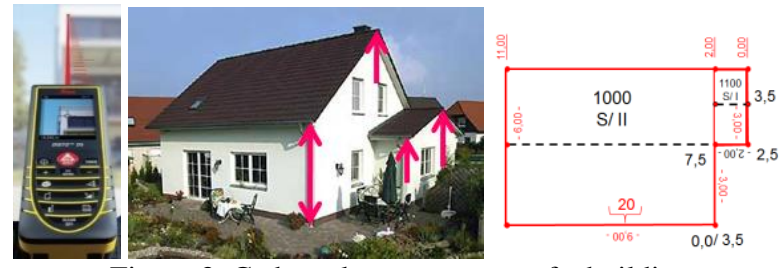

Figure 3. Cadastral measurement of a building

\subsection{Using image matching to close the gap between old LiDAR-data and new built buildings}

The airborne laser scanning data gained by statewide LiDARcampaigns in Bavaria is up to seven years old in particular areas. Beyond that, Bavaria is covered with digital aerial photographs in a 3 year cycle. The ground pixel size of the aerial photographs is approximately $0.2 \mathrm{~m}$. The oriented aerial photographs are also supposed to be used for the acquisition of the 3D-Building Models.

The timed space closure means the later acquisition of buildings for which, at the moment of the first acquisition with automatic building reconstruction from LiDAR-data, the building ground plans from the land registry, but not the height information from LiDAR-data was available. Since the building ground plans from the land registry usually are more actual than the LiDARdata, new buildings which were built after the LiDARcampaign, are the ones which are affected by the timed space closure. Buildings for which, at the time of the first acquisition, height information from LiDAR-data was available, but no building ground plans in the land registry, were not reconstructed. In order to close the actuality gap of the up to seven years old LiDAR-data within the data capturing of the 3D Building Models, a DSM from image correlation (Image Matching) of aerial photographs from the Bavarian surveying flight is processed (Stolz, 2013). Until 2012 the Bavarian photogrammetric campaign was carried out with an overlap of $75 \%$ in longitudinal and $30 \%$ in cross direction. For the production of a high quality DSM and true orthophotos the overlap was improved step by step to $80 \%$ in longitudinal and $50 \%$ in cross direction.

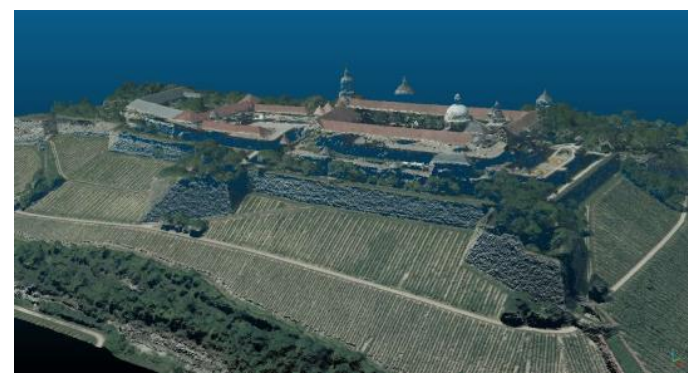

Figure 4. color-coded point cloud from Image Matching

In Bavaria the point density of current LiDAR- campaigns is 4 points per square meter. With Image Matching it is possible to reach a significant higher point density of up to 25 points per square meter due to the ground pixel size of $0.2 \mathrm{~m}$ of the Bavarian Photogrammetry flights.

For computing the surface models from image matching the software "SURE (surface reconstruction)" made by nFrames, was used. Image Matching got a significant impulse from SemiGlobal Matching (SGM) Algorithm (Haala, 2011). In a first step a diffuse cloud of three-dimensional points is computed by $3 \mathrm{D}$ intersections to get a surface model from images. Different pairs of aerial images of the same flight campaign are used to get homologous points in a three-dimensional space by correlation of the image contents. Within the homologous point-cloud points with different levels at the same coordinate (position) may happen. It is also possible, that in very bright or very dark parts of the images poor differences in color and intensity are not sufficient for image matching. This is the reason for some gaps in the point cloud. Each three-dimensional point from image matching has assigned a RGB color value from the original images. In this colored point-cloud roofs and leafs are floating freely in the three dimensional space. Only by suitable averaging (e.g. median) of levels and colors and gridding the resulting irregular point cloud to a regular raster with one representative height value and RGB value for each raster point a surface model is created. Gaps in the data are filled by interpolation of surrounding values. So the resulting surface model is a 2.5 dimensional and colored regular raster. To save computing time the surface model from image matching is produced with a grid spacing of $40 \mathrm{~cm}$ instead of $20 \mathrm{~cm}$ pixel 
size which is the normal pixel size of aerial images produced by the Bavarian Agency for Digitisation, High-Speed Internet and Surveying. This corresponds to a point density of 6 points $/ \mathrm{m}^{2}$ in the new surface model.

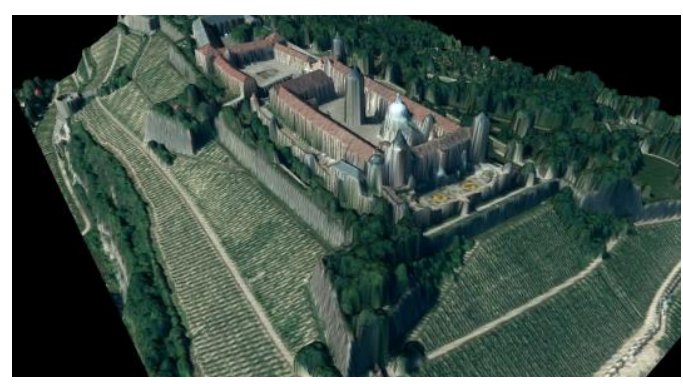

Figure 5. 2.5-dimensional surface model

By calculating the differences between data from LiDAR and the new surface model from image matching it is possible to get information about surface coverings like buildings and sealed soil as well as forest and lower vegetation. Also it is now possible to calculate differences of levels between epochs of data from image matching. This might be used to detect changes in the inventory of buildings or to monitor the growth of biomass. Differences in levels calculated like this can easily be visualized and colorized to see facts affecting levels with their positions and extensions
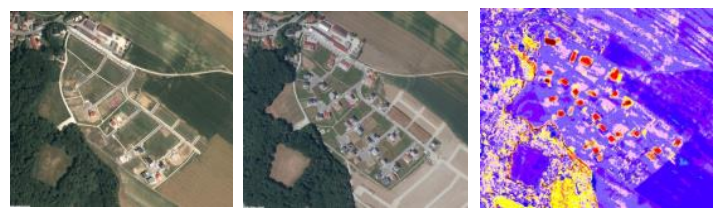

Figure 6. Differential DSM between LiDAR and Image Matching - new buildings are painted in red and areas under construction in violet

\section{THE CENTRAL STORE CONCEPT}

\subsection{Storage of the 3D Buildings}

The data storage is carried out centrally on a relational database with the open source database solution "3D City Database (3DCityDB)". With a database schema (profile) the user has the possibility to create a CityGML conformant data model in the database. The general CityGML profile was further specialized by the AdV for a German-wide standardized acquisition of 3DBuilding Model. 3D-Building models created with this specializations in the AdV-CityGML-profile can be imported with a Java based im- and exporter into the database and exported and visualized in KML and COLLADA format. Additionally, in Bavaria a FME Workbench is used to offer the customers more data export formats like 3D shape, dxf, $3 \mathrm{ds}$ and Trimble SketchUp format skp. Since CityGML is an international standard and several software companies have implemented products and interfaces for the geoinformation market a longtime sustainability of this interface can be expected.

\subsection{Storage of the LIDAR- and DSM-data}

Starting from the ISO standardized LAS data format the LiDAR data and the point-cloud generated from image matching are converted to a binary and compressed LAZ data format. Then these data are stored as binary large objects (BLOB) in a relational database. The files are organized in units of one square kilometer. The data access is done by some batch scripts controlled by a GIS client and LAStools - Software provided by rapidlasso $\mathrm{GmbH}$. The database schema is the same for LiDAR and data from image matching.

\subsection{Big Data}

The storage size for $1 / 3$ of Bavaria is annually 140 TB. For production purposes a maximum of two years or $280 \mathrm{~TB}$ data is necessary. For LiDAR-data additional 10TB is required. The storage size of the product line can be compressed to $10 \%$ by LAZ compression so that in the end 29TB are necessary for the products DTM from LiDAR, the surface model from image matching, the digital orthophoto, the color infrared orthophoto and the true orthophoto.

\section{CONCEPT FOR A SEMANTIC TRANSFORMATION OF 3D BUILDINGS TO INSPIRE}

The basics for changing the aquired 3D-Building Models to INSPIRE by schematic transformation (Aringer et al., 2015) are (figure 7):

- A necessary precondition is the availability of documentation about the schemata of source and target and the rules for transformation between these schemata. On the basis of these documents the schematic transformation can be implemented or can be generated automatically (e.g. (Staub et al., 2008), (Kutzner and Eisenhut, 2010), (Fichtinger, 2011)) if machine-interpretable schemata and transformation rules exist. The transformation tool will produce target data and a report with statistical information about the dataset transformed from the source data.

- Another request for a correct transformation is the compliance of the source data to the source schema and sometimes to further quality criteria. Such quality criteria can be a test specification. On the basis of this specification a test tool for the source data can be implemented or can be created automatically if machineinterpretable test criteria exist (Donaubauer et al., 2010). The test tool creates a report with information about faulty objects and statistics about the tested data. So only correct data are passed to the schematic transformation tool.

Assuming that only correct data are passed to the schematic transformation tool and the transformation rules are correct it is not necessary to have a complex test tool for the target data or a complex event handler within the schematic transformation tool. The correct coding of the target data is ensured by a validation of the schema. Based on this concept a joint research project transformed an AdV-CityGML-Profile-based test data set of Bavarian LoD2 Building Models into an INSPIREcompliant schema. The components of the concept will be shown in the following text.

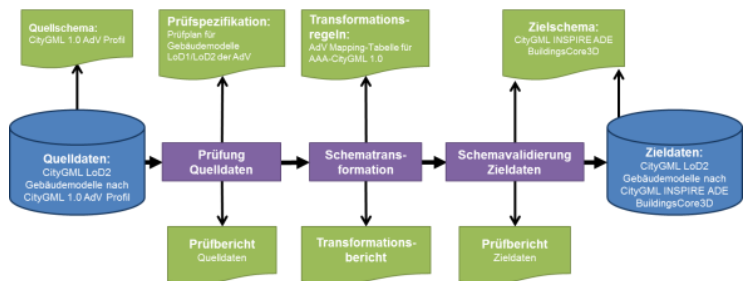

Figure 7. Concept of schematic transformation of 3D Building Models to INSPIRE. 


\subsection{Source schema: AdV CityGML for Building Models}

Source schema of the shown transformation of 3D Building Models is the AdV CityGML standard in the recent version (AdV, 2015a). The AdV CityGML is limiting the general CityGML specification version 1.0 (Gröger et al., 2008) to represent the standard of the AdV Building Model (AdV, 2013). This means, among other things that only the CityGML modules Building, Generics (some extension of Attributes not covered by CitGML standard) and Appearance is allowed. All the other CityGML modules for representation of e.g. vegetation, water or traffic are not part of the AdV CityGML schema. There are also further restrictions in the allowed CityGML Modules. In the module Building of the AdV-Profile only LoD1 and LoD2 are allowed. The attributes function and measuredHeight are not optional but obliged. Further on the elements of the building envelope have to be grouped to RoofSurface-, WallSurface-, GroundSurface- and ClosureSurface-Objects. The AdV profile defines not only limitations of standard CityGML but also some extensions. These extensions are Application Domain Extensions (ADE) (see 4.2) but with fix generic attributes. The aim of this extension is to keep quality information for single building objects. The generic attributes like origins of the roof height, address and ground level as well as the reference point of the roof is stored as codes defined in the AdV profile.

\subsection{Target schema: INSPIRE Data Specification on Buildings / CityGML INSPIRE ADE}

The INSPIRE-directive defines deadlines for providing INSPIRE conform data coming from the Implementing Rules on interoperability of spatial data sets and services. But there is no specification for a data-model of specific themes. For providing INSPIRE conform data additional regulations are applicable. These regulations give detailed information about nature and scope of the data content e.g. by definition of object types or mandatory attributes. There is also the "Technical Guidance" for each theme. The Technical Guidance is not legally binding but contains e.g. complete data models and technical details. For 3D Building Models combined with the digital terrain model (DTM) the INSPIRE Technical Guidelines for height (annex II) and Building Models (Annex III) have to be considered. The documents "D2.8.II.1 Data Specification on Elevation" and "D2.8.III.2 Data Specification on Buildings" are relevant as well. This specification was published on December $13^{\text {th }} 2013$ and came to effect retroactively as of October 2013. For the directive new gathered or updated data defined in annex II or III were to be provided in an interoperable way until 2015. The other data have to be provided until 2020. Actually the German nationwide dataset of Building Models in LoD1 would have to be provided in an interoperable way for the requirements of the INSPIRE directive until 2020.

To deal with various applications for the use of building information as well as with different types of building data for the European Union, four profiles were defined, which are different in the scope of semantically and geometrically representable information. (figure 8).

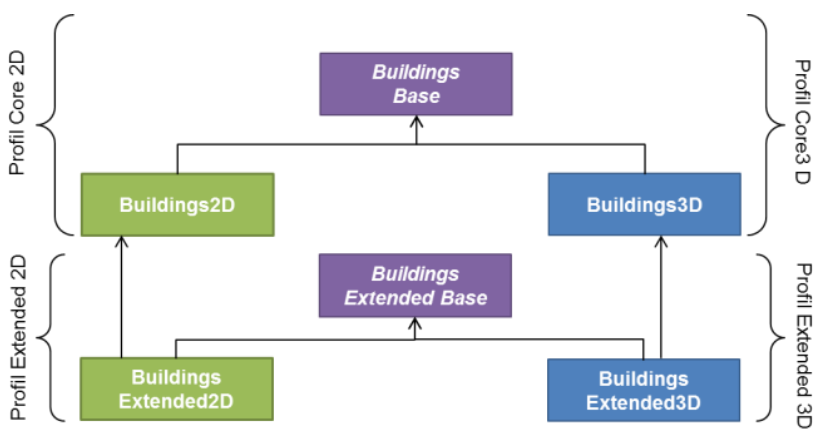

Figure 8. Profiles of the INSPIRE specifcation for Building Models. Figure modified from (Gröger and Plümer, 2014)

The profile "Core 2D" for 2D- and 2.5D-Building data is only containing basic semantic information. These are defined in the abstract application schema BuildingsBase. The profile "Core $3 \mathrm{D}$ " is based on the semantic of BuildingsBase as well, but it is extending BuildingBase by concepts for three dimensional representation of building envelope in the levels of detail from one to four which are matching the definition of CityGML. The profiles "Core 2D" and "Core 3D" constitute the normative part of the INSPIRE Building Model.

The application schema BuildingsExtendedBase and the derived schemata BuildingsExtended2D and BuildingsExtended3D are capable for modelling much more comprehensive semantic information (Gröger and Plümer ,2014).

The INSPIRE specification does not require a special data format for the transfer of data, but it defines GML (ISO 19136) as default coding and provides XML schema files for validation. That format is called "INSPIRE BU". Specifically, (Gröger and Plümer, 2014) since the two 3D profiles of the specification of Building Models are based strongly on CityGML and many tools for processing CityGML data already exist, the INSPIRE specification provides an extension of the CityGML standard as an option for coding. This is done by a so called CityGML Application Domain Extension (ADE). For all concepts (classes, attributes, geometries and constraints) in this CityGML INSPIRE ADE (Gröger et al., 2013) which are as well part of CityGML as part of INSPIRE the concepts of CityGML are used. Those concepts from the INSPIRE Building Model which are not existing in CityGML for the ADE the elements from INSPIRE are taken. For example there is the INSPIRE specific common attribute inspireID which is a unique identifier for objects. The attributes beginLifespanVersion and endLifespanVersion are defined to represent timestamps of transactions. Also the conditionOfConstruction is defined to store the condition of buildings like planned, under construction, in use etc. An important difference to CityGML is the use of complex data types for thematic attributes. For example, by the use of the complex data type elevation besides the scalar height value it is possible to specify at which part of the building the height was measured (e.g., highestEave for the highest part of the eave of a building or generalRoof for the average height of the roof).

\subsection{Transformation rules: ADV mapping table for AAA - CityGML 1.0}

The basis for a model-based transformation of the schema is the availability of transformation rules on the level of the underlying schemata. To transform 3D-BuildingModels in level of detail 2 to INSPIRE, the ADV-project group "3D-geo base data" developed a mapping table based on the AdV-CityGMLprofile and GeoInfoDok 7.0 beta (AdV, 2015b). Originally, the 
mapping table included all classes of the CityGML building module and their correlates in the AAA-model according to the GeoInfoDok 7.0 and to the INSPIRE Data Specification on Buildings (Profil BuildingsExtended3D) and was expanded with a mapping to the CityGML INSPIRE ADE Core 3D standard within the research project described in this paper. Table 2 shows exemplary the mapping between schemata on the level of the most important object classes. Important to note is 1:1 mapping between the classes of the schema. One consequence is the resulting low complexity of the schema transformation.

\begin{tabular}{|l|l|l|l|}
\hline $\begin{array}{c}\text { AdV-CityGML- } \\
\text { Profil }\end{array}$ & \multicolumn{1}{|c|}{ AAA 7.0 } & \multicolumn{1}{|c|}{$\begin{array}{c}\text { INSPIRE } \\
\text { Building } \\
\text { Extended 3D 3.0 }\end{array}$} & $\begin{array}{r}\text { CityGML } \\
\text { INSPIRE } \\
\text { Buildings } \\
\text { Core3D ADE }\end{array}$ \\
\hline bldg:Building & $\begin{array}{l}\text { AX_Bauteil3D } \\
(101009)\end{array}$ & $\begin{array}{l}\text { BuildingsExtended } \\
\text { Base::Building }\end{array}$ & bldg:Building \\
\hline bldg:RoofSurface & $\begin{array}{l}\text { AX_Dachflaeche3D } \\
(101003)\end{array}$ & $\begin{array}{l}\text { BuildingExtended3D:: } \\
\text { RoofSurface }\end{array}$ & bldg:RoofSurface \\
\hline bldg:WallSurface & $\begin{array}{l}\text { AX_Wandflaeche3D } \\
(101005)\end{array}$ & $\begin{array}{l}\text { BuildingExtended3D:: } \\
\text { WallSurface }\end{array}$ & bldg:WallSurface \\
\hline bldg:GroundSurface & $\begin{array}{l}\text { AX_Bodenflaeche3D } \\
(101004)\end{array}$ & $\begin{array}{l}\text { BuildingExtended3D:: } \\
\text { GroundSurface }\end{array}$ & bldg:GroundSurface \\
\hline bldg:ClosureSurface & $\begin{array}{l}\text { AX_Abschluss } \\
\text { flaeche3D (101002) }\end{array}$ & $\begin{array}{l}\text { BuildingExtended3D:: } \\
\text { ClosureSurface }\end{array}$ & bldg:ClosureSurface \\
\hline
\end{tabular}

Table 1. Mapping between the schemata AdV-CityGML-Profil,

AAA 7.0, INSPIRE Building Extended 3D 3.0 and CityGML

INSPIRE Buildings Core3D ADE on the level of object classes

\subsection{Test plan to assure quality of 3D-Building Models}

Since mid-year 2013 it is possible for states to provide 3DBuilding Models in level of detail 1 to (ZSHH) "Zentrale Stelle Hauskoordinaten und Hausumringe", which is a central crossnational distribution agency. ZSHH provided a guideline how to validate 3D-Building-Models. This guideline enabled states to check the conformity of their level of detail 1 data in CityGML-format to the ADV-schema. Additional test criteria like geometric constraints would be desirable. A first approach to test CityGML city models is provided by the validation software CityDoctor of the University of Applied Science (Hochschule für Technik) in Stuttgart (Wagner et al., 2014).

The LA Geobasis commissioned the state North-Rhine Westphalia to provide a quality assurance plan for the data in level of detail 1 and 2 of the German states. This measure was to ensure conformity between the data of the different states and to enable the transfer into the database at ZSHH. The software component should allow for quality assurance at the level of the states providing data as well as at ZSHH receiving data.

The ADV-project group "Geobasisdaten" and ZSHH jointly developed the respective criteria for data at LoD1 and 2. The test criteria defined in the test plan were developed based on experience in building the data bases and the experience in cooperating within $\mathrm{ZSHH}$. The test criteria can be categorized as follows:

- Test of schema: Conformity of the dataset with the XMLschema.

- Profile conformity: Conformity of the dataset with the profiles of $\mathrm{ADV}$, i.e. e.g. existence and correct configuration of the generic attributes defined in the ADVCityGML-profile, non-redundant saving of geometry, no fragmentation of building parts in further parts.

- Geometry: Check of geometry, is the frame closed (waterproof)? Are the height specified in the attribute "measuredHeight" and the height of the building geometry the same?

- Semantics: Are all vertical surfaces modelled as wall surfaces (WallSurface-object)?
All criteria are listed in (AdV, 2015c). The test plan version 1.2 dated from 28.01.2015 was included in the statement of work in the tender of ZSHH for a testing software, after the decision of LA Geobasis to tender the software. Since September 2015, the test software for quality assurance of 3D-Building-Models is available for at $\mathrm{ZSHH}$ before data enter the database as well as for the states to check data. In the meantime, the test plan was updated to version 1.3; it is expected that the extended test procedure will be implemented.

Unified tests for semantic and geometry are currently defined by OCG in the "CityGML Quality Interoperability Experiment". The ADV project group "Geobaisdaten" will be required to implement the results into the test protocol and eventually enhance with the specifics of the AdV-CityGML-profile.

The test protocol is discussed in the working group quality of the SIG-3D. As the discussions of the working group quality of the SIG-3D regarding test protocols are used in the "CityGML Quality Interoperability Experiment" of the OCG, that itself is responsible for the definition of unified test criteria, e.g. for semantic and geometry.

\subsection{The test routine}

The tests for 3D Building-Models in the levels of detail one and two to check conformity of schema and profile as well as geometric and semantic data checks defined by the AdV have been implemented with $\mathrm{FME}^{1}$ software as so called FME Workbenches ${ }^{2}$. Result of the test routine is an Excel file with one sheet listing all faulty elements per test criteria. On an additional sheet there is an error statistic as well. The next table is showing excerpts of the error statistic for a dataset of level of detail 2 Building models produced by the Bavarian Agency for Digitisation, High-Speed Internet and Surveying. The column "error type" is showing numbers defined in the proof plan of the AdV. In the column "Filename" there is the dataset where the error was found. The shown numbers of the proof plan represent geometric tests like:

- Are all Building-Model solids water proof?

- Are all Building models free of self intersections?

- Are all surfaces planar?

- Are all normal vectors directed to outside?

- Are all wall surfaces vertical?

The column "Errors (percent)" is showing the percentage of objects with the particular error. In this example $6.6 \%$ of the 424 Building Models or $0.3 \%$ of the 2655 wall surfaces in the tested dataset are faulty in that way.

\begin{tabular}{|l|l|l|l|} 
File name & FeatureType & Error type code & $\begin{array}{l}\text { Errors } \\
\text { (percent) }\end{array}$ \\
\hline $4485 \_5490$ & Building & $3110 \_3120 \_3140 \_3310 .$. & 6.6 \\
\hline $4485 \_5490$ & WallSurface & Error code 3150 & 0.3 \\
\hline
\end{tabular}

Table 2. Example for an error statistic for a LoD2 dataset

All tests could be implemented with FME software. During the operational work at the Bavarian Agency for Digitisation, HighSpeed Internet and Surveying it was shown, that errors are detected reliably but the runtime for testing big data should be improved.

\footnotetext{
${ }^{1} \mathrm{http}: / /$ www.safe.com/fme/fme-desktop/

${ }^{2}$ In FME software transforming data is organized as so called „FME-Workspace“ which integrates reading, writing and a sequence of analyzing and transforming processes (con terra, 2015).
} 


\subsection{Transformation of the schema}

Before implementing the transformation of the schema was possible, the mapping table provided by the AdV was reviewed for completeness and accuracy of the transformation rules between CityGML 1.0 AdV profile and INSPIRE by a joint research project of the Bavarian State Agency for Surveying and Geoinformation and the TUM, Chair of Geoinformatics. It turned out, that the rules were not described machineinterpretable. For example it was not clear, whether the table contents meant the UML data model or the derived XML schemata.

Also the transformation rules were not precise enough for some attributes. This applies to some attributes, in which simple data types from the source schema must be mapped to complex data types from the INSPIRE schema. For example the CityGMLname attribute which type is CharacterString has to be mapped to the INSPIRE-name attribute that is GeographicalName-type which is quite complex. Also it is necessary for some attributes to create mapping lists for values because of different value ranges between the schemata. Exemplarily this applies to the attributes "verticalGeometryEstimatedAccuracy" and "horizontalGeometryEstimatedAccuracy" in the target schema which is a scalar value with the type length but in the source schema it is a code describing the estimated accuracy. The following table shows an example of a corresponding part from source-data and target-data. In that example the source-data are providing the code " 1000 " which means data gathered by LiDAR. The targetschema is requesting a scalar value. In the example it is set to $0.2 \mathrm{~m}$. This is done by a value assignment list.

\begin{tabular}{|l|l|}
\hline \multicolumn{1}{|c|}{ AdV-CityGML-Profile } & \multicolumn{1}{c|}{$\begin{array}{c}\text { CityGML INSPIRE Buildings Core3D } \\
\text { ADE }\end{array}$} \\
\hline $\begin{array}{l}\text { <gen:stringAttribute } \\
\text { name="DatenquelleDachhoehe"> } \\
\text { <gen:value>1000</gen:value> } \\
\text { </gen:stringAttribute> }\end{array}$ & $\begin{array}{l}\text { <bu-core3d-ade:verticalGeometryEstimatedAccuracy } \\
\text { uom="urn:ogc:def:uom:OGC:1.0:metre">0.2 } \\
\text { </bu-core3d- } \\
\text { ade:verticalGeometryEstimatedAccuracy> }\end{array}$ \\
\hline
\end{tabular}

Table 3. Code example to compare attributes for geometric accuracy.

Additional value assignment lists are required to complete the transformation rules for following attributes or coded lists:

"DatenquelleBodenhoehe" is mapped to "verticalGeometry Reference3DBottom" and it is not clear whether the attributes "Lowest Floor Above Ground" or "Bottom of Construction" would be not be the better choice. The attribute "function" is mapped to "currentUse". The attribute "RoofTypeTypeAdV" corresponds to "roofType Value" and "Datenquelle Bodenhoehe" is mapped to "ElevationReferenceValue".

The rules coming from the mapping tables were implemented as FME-Workbench. The FME-Workbench can read CityGML data in LoD1 and LoD2, which comply to the CityGML 1.0 $\mathrm{AdV}$ profile and the proof plan for Building-Models. Also the FME-Workbench is transforming the read data to CityGML INSPIRE ADE BuildingsCore3D. Since the mapping table, as described above, is not complete, it was necessary to make some assumptions for a correct mapping or, in case of missing value mapping lists dummy-values were set. In the practical work of the transformation an inconsistency in the XML-files of the INSPIRE-schema was detected. The INSPIRE BU XMLschema is importing other INSPIRE XML schemata, which import additional INSPIRE XML schemata that are based on different versions of the INSPIRE Data Specification. The different versions of the schema have different namespace URIs abbreviations. But in INSPIRE instance documents they should have identical namespace prefixes. To work around this problem, the INSPIRE-schemata were modified. The FME-
Workbench only works correctly with this modified INSPIREschema. For validating the XML-files of the transformed data the original INSPIRE-schema was used. Using the XMLschema files of the "CityGML INSPIRE ADE" did not cause further problems for the standard component to export CityGML with the FME software.

At the same time with the research cooperation reported here, there was a Bachelor thesis (Popp, 2015) at TU München. in which the default coding „INSPIRE BU“ instead of CityGML INSPIRE ADE was tested. The FME-Workbench was more complex because not only semantic but also geometric transformations had to be done. This was necessary because the Building-Models of the source data consist not only of the building-envelope, but also the terrain intersecting line (lod2TerrainIntersection). The CityGML-Writer component of the FME software can handle that. The INSPIRE-GML component of FME software cannot.

\section{CONCLUSION}

It could be shown that the transformation to the INSPIRE schema „INSPIRE BU“ and „CityGML INSPIRE ADE“ of 3DBuilding-Models from those provided by the German States based on LiDAR, Dense Image Matching or the cadastre is possible with the mapping table from the AdV and commercial software tools. The concept developed aims at analyzing the source data to the corresponding test specification. As a consequence, the transformation can be quite simple because complex handling of errors and exceptions is obsolete.

The evidence from the research on schematic transformation exemplarily shows the required clarifications of mapping table results in the update of mapping table and FME-Worksbench by the AdV "Projektgruppe 3D-Geobasisdaten". Especially mappings for simple data types in the source schema to complex data types in the target schema were added. Also missing value assignment lists for some attributes and code lists were created. The FME-Workbench based on "CityGML INSPIRE ADE" was adapted and checked using data from some German states. The surveying administrations of the German states started early in applying international standards to capture nationwide semantic 3D-Building-Models. The studies described herein show that using the international standardized data format CityGML as well by the AdV for the national schema as by the INSPIRE working group for defining the INSPIRE specification for Building Models, is supporting the ability to transform the data. The chosen process ensures that the INSPIRE for 2020 requirements can be achieved. The necessary actions for a nationwide application still need to be decided by the AdV.

\section{REFERENCES}

AdV, 2013. Produktstandard für 3D-Gebäudemodelle 1071R2, http://www.adv-online.de/AdV-Produkte/Standards-undProduktblaetter/Standards-der-Geotopographie/.

AdV, 2014. Dokumentation zur Modellierung der Geoinformationen des amtlichen Vermessungswesens (GeoInfoDok), Version 7.0beta, data on file.

$\mathrm{AdV}, 2015 \mathrm{a}$. AdV-CityGML-Profile für 3D-Gebäudemodelle Ergebnisse der $P G$ „3D-Gebäudemodelle“ der AdV, 17.01.2015, http://www.adv-online.de/AdVProdukte/Standards-und-Produktblaetter/Standards-derGeotopographie/. 
AdV, 2015b. Mapping-Tabelle für AAA-CityGML1.0, 22.05.2015, http://www.adv-online.de/AdVProdukte/Standards-und-Produktblaetter/Beispielsammlungen/.

AdV, 2015c. Prüfplan 3D-Gebäudemodelle in der Version 1.3 und $1.2 \mathrm{http}: / / \mathrm{www} . a d v-o n l i n e . d e / A d V-P r o d u k t e / S t a n d a r d s-$ und-Produktblaetter/Beispielsammlungen/.

Aringer, K., Donaubauer, A.; Kolbe, T.H., Roschlaub, R., 2015. Modellbasierte Transformation von 3D-Gebäudemodellen nach INSPIRE - erste Ergebnisse, zfv - Zeitschrift für Geodäsie, Geoinformation und Landmanagement, submitted 14.12.2015.

Aringer, K., Roschlaub, R., 2014. Bavarian 3D Building Model and Update Concept Based on LiDAR, Image Matching and Cadastre Information, , In: Umit Iskidag (ed.), Lecture Notes in Geoinformation and Cartography, Innovations in 3D GeoInformation Sciences, 2014, Springer International Publishing Switzerland, pp. 143-157.

Aringer, K., Hümmer, F., 2011. Die dritte Dimension im Kataster - Aufbau eines landesweiten Gebäudemodells am Beispiel Bayerns, zfv - Zeitschrift für Geodäsie, Geoinformation und Landmanagement, 2011, 136(4), pp. 210-218.

con terra, 2015. FME Desktop, Wichmann.

Donaubauer, A., Kutzner, T., Gnägi, H. R., Henrich, S., Fichtinger, A., 2010. Webbasierte Modelltransformation in der Geoinformatik. Modellierung 2010, Gesellschaft für Informatik, pp. 269-284.

Fichtinger, A., 2011. Semantische Transformation im Kontext von INSPIRE - dargestellt am Beispiel der grenzüberschreitenden Bodenseeregion, Dissertation, Technische Universität München.

Gröger, G., Kolbe, T.H., Czerwinski, A., Nagel, C., 2008. OpenGIS City Geography Markup Language (CityGML) Encoding Standard, Open Geospatial Consortium.

Gröger, G.; Kutzner, T.; Kolbe, T.H., 2013. A CityGML-based encoding for the INSPIRE Data Specification on Buildings, INSPIRE Conference 2013.

Gröger, G., Plümer, L., 2014. Das Gebäudemodell der Initiative INSPIRE, In: zfv - Zeitschrift für Geodäsie, Geoinformation und Landmanagement, 2014, 139(2), pp. 90-102.

Gruber, U., Riecken, J., Seifert, M., 2014. Germany on the Way to 3D-Cadastre. In: zfv - Zeitschrift für Geodäsie, Geoinformation und Landmanagement, 2014, 139(4), pp. 223-228.

Haala, N., 2011. Multiray Photogrammetry and Dense Image Matching, Photogrammetric Week 2011, Wichmann Verlag, Berlin/Offenbach, pp. 185-195.

INSPIRE, 2013. INSPIRE Thematic Working Group Buildings: D2.8.III.2 Data Specification on Buildings - Draft Technical Guidelines, Version 3.0rc3, 2013.

Janowsky von, D., Ludwig, R., Roschlaub, R., Streuff, H., 2010. Geodateninfrastrukturrecht in Bund und Ländern, Kommunal- und Schulbuchverlag, Wiesbaden.

Kutzner, T., Eisenhut, C., 2010. Vergleichende Untersuchungen zur Modellierung und Modelltransformation in der Region
Bodensee im Kontext von INSPIRE, Technische Universität München. http:// mediatum.ub.tum.de/doc/1223763/166974.pdf

LA Geobasis, 2011. Anlage zum Beschluss 2/4 des Lenkungsausschusses Geobasis vom 12.04 .2011 über die Einrichtung einer Zentralen Stelle für die Bereitstellung von Hauskoordinaten und Hausumringen, geändert durch Beschluss 4/1 des Lenkungsausschuss Geobasis vom 01.12.2011.

Popp, L., 2015. Semantische Transformation von 3DGebäudedaten nach INSPIRE. Bachelorarbeit im Studiengang Geodäsie und Geoinformation, Technische Universität München.

Rottensteiner, F., Sohn, G., Jung, J., Gerke, M., Baillard, C., Benitez, S. and Breitkopf, U., 2012. The ISPRS Benchmark on Urban Object Classification and $3 D$ Building Reconstruction, ISPRS Annals of the Photogrammetry, Remote Sensing and Spatial Information Sciences, Volume I-3, XXII ISPRS Congress, 25 August - 01 September, Melbourne, Australia.

Rottensteiner, F., Briese, Ch., 2003. Automatic generation of building models from lidar data and the integration of aerial images. In: International Archives of Photogrammetry, Remote Sensing and Spatial Information Sciences, Dresden, Germany, Vol. XXXIV, Part 3/W13, pp. 174-180.

Schilcher, M., Guo, Z., Klaus, M., Roschlaub, R., 1998. Semi Automatic Derivation of 3D-City-Models from existing $2 D$ Geoinformationsystems, Spatial Information Science and Technology SIST, 13. - 16. December, Wuhan, China.

Schilcher, M., Guo, Z., Klaus, M., Roschlaub, R., 1999. Aufbau von 3D-Stadtmodellen auf der Basis von 2D-GIS, Photogrammetrie - Fernerkundung - Geoinformation (PFG), No. 3, pp. 157-170.

Schilcher, M., Roschlaub, R., 1999. Fortführung und Wiederverwendbarkeit von 3D-Stadtmodellen durch Kombination von GIS und Photogrammetrie, Festschrift aus Anlass des 60. Geburtstags von H. Ebner, TU München, pp. $267-281$.

Staub, P., Gnägi, H.R., Morf, A., 2008. Semantic Interoperability through the Definition of Conceptual Model Transformations, Transactions in GIS 12, pp. 193-207.

Stolz, M., 2013. Digitale Oberflächenmodelle aus Bildkorrelation, DVW - Gesellschaft für Geodäsie, Geoinformation und Landmanagement e.V., No. 2, pp. 139-150.

Vosselman, G., 2002. Fusion of laser scanning data, maps and aerial photographs for building reconstruction, IEEE International Geoscience and Remote Sensing, Symposium, 2428 June, Toronto, Canada, on CD-ROM, pp. 85-88.

Wagner, D., Kolbe, T.H., Coors, V., 2014. Spezifikation von Prüfplänen und Prüfergebnissen zur Validierung von $3 D$ Stadtmodellen. In: DGPF Tagungsband 23 / 2014. 